\title{
A qualitative analysis of Muslim young adults' adaptation experiences in New Zealand
}

\section{Jaimee Stuart}

Roy McKenzie Centre for the Study of Families

Victoria University of Wellington, New Zealand

Authors' note: Address all correspondence to Jaimee Stuart, Roy McKenzie

Centre for the Study of Families, Victoria University of Wellington, PO Box 600 , Wellington, New Zealand. This research was funded by a Sasakawa Young Leaders Fellowship Fund (SYLFF) scholarship.

\section{Abstract}

Muslim youth living in Western countries are thought to face a variety of risks to their adjustment, although according to recent research they do not necessarily have negative outcomes in comparison to non-Muslims. In order to examine the complexities of development for Muslim youth in the West, it is necessary to have a comprehensive understanding of their lived experiences within their intercultural context. Therefore, this research study qualitatively investigated the indicators and determinants of participation and success for Muslim young adults in New Zealand. The results of this study enabled a framework to be developed that illustrates the most salient ecological resources youth access (family, religion and the intercultural environment), the risks they face (discrimination and cultural differences), and outcomes of the acculturation process. Results indicate that while Muslim youth in New Zealand may be at risk of maladaptative outcomes because of their exposure to discrimination and cultural transition stressors, ecological resources may counteract some of the negative effects of these stressors and enable these young people to become resilient.

Due to the large number of permanent migrants from Muslim-majority nations to the Western world, Islam has become the second largest religion following Christianity in a number of European countries (Sirin \& Fine, 2008). Over 300 
million immigrant and ethnic minority Muslims now live in countries where Islam is not the majority religion. Within these contexts, the international politicization of Islam and the increased social anxiety toward this group has meant that Muslim communities have become the targets of discrimination, prejudice, and negative media coverage (Pew Research Center, 2009). Muslims living in Western contexts often must attempt to achieve positive adaptation (the relatively stable psychological and behavioral changes that take place in an individual or group in response to demands in the environment; Berry, 1997) in a context where they are minorities in a two-fold sense, both in terms of their religion and their ethnicity.

The task of successfully adapting to life within a Western environment is particularly complex for young immigrants who face the task of emotional and physical maturation as well as acculturation (the behavioral and psychological changes that are a result of cultural transition; Sam, 2006). For Muslim immigrant youth who are growing up in environments where their religious orientation is a cause of social tension, this is even more difficult. As Sirin and Fine (2007, p. 151) suggest: "When one's social identity is fiercely contested by the dominant discourse ... one of the first places we can witness psychological, social, and political fallout is in the lives of young people."

Despite the increased levels of public scrutiny, discrimination, and adaptation difficulties faced by Muslim young people in their development and acculturation, very little research has examined the psychological effects of growing up Muslim in a Western context. Furthermore, in a review of the few available studies, Balsano and Sirin (2007) found that most studies focus on gender issues (with specific reference to veiling), the majority involve Arab Americans, and most predominantly dealt with religious or political issues. This research agenda has resulted in a lack of systematic and generalizable psychological studies investigating the experiences (both positive and negative) of Muslim youth in the West.

Although there is little research on Muslim youth, there is a widespread opinion that these young people are at risk of maladaptation due to their membership in a social group that is the subject of discrimination (Franz, 2007; Inglehart \& Norris, 2009). Indeed, maintaining a strong religious identity in a context where there is a prejudice against one's group can be very difficult. Smith (2002) suggests that Muslims are often are considered to be foreigners if they maintain their religiosity, potentially meaning that integration could be "at the price of . . becoming less Muslim" (Smith, 2002, p. 14). This is concerning considering the important resources that can be provided by a religious identity and the large degree to which Muslim migrants currently identify with their religious community. For instance, research conducted by Anwar (1998) with Asian immigrants in the United Kingdom found that three-quarters of young Muslims thought religion was very important for the way they lived 
their life, and for Muslims, (unlike other religious groups in their study) the second-generation maintained the value of and centrality of their religious identity.

Although there are thought to be inherent risks for Muslim youth in Western contexts, international research has found that Muslim immigrants do not necessarily experience higher levels of maladjustment in comparison to other religious and non-religious groups. A recent international study on youth adjustment found that Muslim youth have high levels of both psychological and sociocultural adaptation overall (Sam, Vedder, Ward, \& Horenczyk, 2006). Also, research with Muslim migrant youth in Norway found that these young people have fewer mental health problems than other non-Western immigrant groups and are not at risk of increased psychiatric problems compared to their non-immigrant counterparts (Oppedal \& Røysamb, 2007).

Effectively, even though Muslim young people experience a variety of risks during acculturation, especially in regard to prejudice and discrimination, they also manage (in some cases) to achieve positive adaptation. Therefore, it is suggested that previous ways of conceptualizing the acculturation process for this group (as inherently risky and leading to poor adaptation), do not fully capture the reasons why these young people successfully manage the acculturation process. In fact, it may be that Muslim youth's religious identification is not progressively weakened or diluted as a result of their living in a Western context, but rather that this identification takes on new meanings and functions (Beckford, Glae, Owen, Peach, \& Weller, 2006; Robinson, 2009). Kong (2010) proposes that religious identities can be a strong and positive tool for young people to subvert negative (discriminatory) discourses, and Archer (2001) argues that religious identity helps young Muslims to reject cultural loss, while unifying individuals as members of a global community of believers.

\section{The Context of the Research: Muslims in New Zealand}

The Ministry of Social Development (2008) reported that while Muslims are a numerically small group numbering approximately $36,000^{1}$ individuals and representing only $1 \%$ of the overall New Zealand population, they are the most rapidly growing religious group in New Zealand. They also find that Muslim immigrants come from diverse ethnic backgrounds and national origins. The majority (77\%) of New Zealand Muslims are overseas-born with the largest proportions identifying ethnically as Indian (29\%) and as members of Middle Eastern groups (21\%) such as Arabian, Iranian, and Iraqi. The Muslim population is also very youthful, with $61 \%$ under the age of 15 in comparison to

1. Although unofficial estimates by the Federation of Islamic Association of New Zealand (FIANZ) suggest that the actual figure is perhaps as high as 40-45,000 (Kolig \& Kabir, 2008). 
the wider society, where only $25 \%$ of the population is under the age of 15 (Statistics New Zealand, 2011). In New Zealand, Muslim peoples represent a relatively new immigrant minority group, meaning that this group is potentially in a precarious position in terms of cultural exclusion and isolation. They also face unique challenges with regards to intra-community diversity and attending to the distinct needs of youth, particularly concerning religious and cultural transmission (Kolig \& Kabir, 2008).

Increasing religious diversity is a significant feature of public life, and as a nation New Zealand acknowledges that communities have a positive role to play in society and the country must recognize the rights to religion, the responsibilities of religious communities, and the responsibilities of the wider society to encourage freedom of expression and tolerate variations in beliefs and behaviors (HRC, 2010). Yet as a society, currently very little is being done in order to achieve these goals for the Muslim community. It is evident that in New Zealand there is what Kolig and Kabir (2008, p. 274) label a "diffuse practical sense of ethnic and cultural tolerance", meaning that while levels of prejudice are reasonably low and endorsement of integration is generally high, few voices are heard that promote a positive view of Muslim immigration.

However, Muslim youth in New Zealand seem to be faring well psychologically. In fact, recent research has found that these youth report greater life satisfaction, fewer behavior problems, and fewer symptoms of psychological distress than both Maori (indigenous) and Pākehā (New Zealand European) youth (Stuart \& Ward, 2011; Stuart, Ward, \& Adam, 2010; Ward, Liu, FairbairnDunlop, \& Henderson, 2010). Yet, there is still very little that is known qualitatively about Muslim youth (immigrant or otherwise) living in New Zealand and many questions about their developmental experiences remain unanswered. For example, what does it mean for a Muslim young person when their social group is perceived to be a threat to the wider society? How do the perceptions and representations of Islam impact upon a young person's sense of self? How do these young people negotiate the potentially conflicting elements of their social identities (religious, ethnic, and host national)? Do they experience value conflicts and confusion? Furthermore, how does this negotiation process affect psychological and sociocultural adaptation to the host society of Muslim immigrant youth?

\section{The current study}

In order to examine the complexities of Muslim immigrant youth acculturation in New Zealand, it is necessary to have a comprehensive understanding of their lived experiences within this context. To achieve this outcome, the current research is qualitative and exploratory in nature, utilizing the strengths 
of this methodology to draw out relevant themes and concepts where no systematic theory has been previously identified (Patton, 2002). Specifically, this study will examine the following questions: (1) How do Muslim young adults acculturate in the New Zealand environment? and (2) What factors promote or detract from positive adjustment under these conditions?

\section{Method}

\section{Participants}

Ethical approval was granted by the Victoria University of Wellington Psychology ethics committee. Individuals were invited to participate in the study if they were a minimum age of 16 years and self-identified as a Muslim immigrant young person. Participants were sought from a variety of different backgrounds and ages in order to capture a diversity of experiences. Individuals were given the choice of being able have a one-on-one interview, or participate in a focus group. This resulted in a total of 24 participants who took part in the study, 17 through face-to-face interviews and 7 through two focus-group sessions of 3 and 4 participants, respectively. Interviews and focus groups ranged from between half an hour and close to two hours in length, with over 20 hours of data in total. The interview sample consisted of 7 males and 10 females, who came from the Middle East (8), Southeast Asia (5), South Asia (3), and Africa (1). The focus group sample consisted solely of females who came from South East Asia (7). The average age of the participants was 20.1 years, and the ages ranged from 19-24. All of the participants were first-generation immigrants to New Zealand, although length of residence and migration histories varied significantly.

\section{Procedure}

Participants were initially recruited through advertisements distributed via student support services, the Muslim students club and the Muslim prayer room at Victoria University of Wellington, New Zealand. They were informed that the study was about their experiences in New Zealand as Muslim young people and were given the option to either engage in a one-on-one interview or in a focus group at the location of their choice. These options were presented in order to allow participants to feel comfortable enough to share their experiences. Following initial recruitment, more participants were sourced through snowballing and word of mouth. Patton (2002) suggests that the sample size in qualitative research depends on what one wants to know and how the findings will be used. In the current study, sampling decisions were based on the 
principle of theoretical saturation, meaning that subsequent data were no longer yielding novel information (Floersch, Longhofer, Kranke, \& Townsend, 2010; Patton, 2002). Data collection was assisted by a semi-structured interview schedule consisting of 10 questions focusing on experiences of adaptation (see Table 1). For the sake of confidentiality, all identifying information was removed from the interview transcripts and participants were assured that their recorded interviews/focus and written transcripts would not be read in their entirety by anyone other than the researcher. Furthermore, throughout the course of the study informal engagement with the Muslim community was maintained which led to a large set of field notes which were collated and included as part of the interpretative analysis.

TABLE 1. Prompt questions

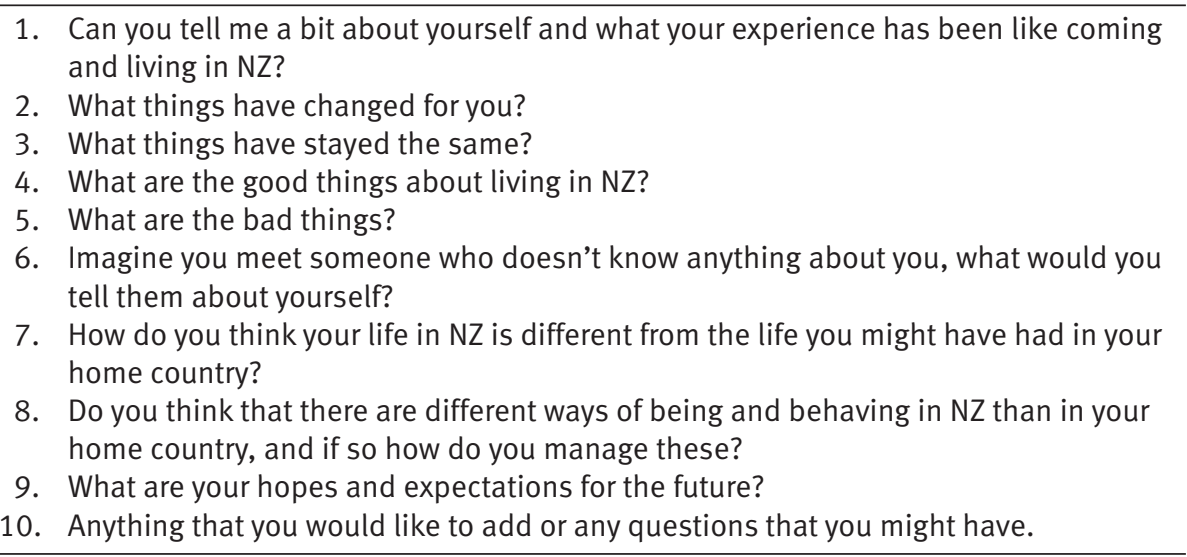

\section{Data Analysis}

Thematic Analysis was utilized due to the flexible nature of this technique, which suited the high complexity of the information and the lack of a prio$r i$ theories or conceptual models available to guide coding (Braun \& Clarke, 2006). Thematic Analysis is a technique which focuses on analyzing information by finding recurring patterns in the data, making inductions based on knowledge of the subject area, condensing information into emergent topics and subsequently describing these as key themes (Boyatzis, 1998; Braun \& Clarke, 2006). From the thematic analysis, a large set of themes emerged, and these were then reduced by conducting an in-depth interpretative analysis with an aim to discover the barriers and opportunities Muslim young people face as ethnic and religious minorities, and how positive adjustment is obtained under these conditions. This resulted in the framework illustrated in figure 1. A validity assessment of the final dataset was produced by: (1) double-checking 
to assure that codes were consistently applied across all interviews, (2) double- checking to assure codes were appropriately grouped under the thematic categories, and (3) double-checking to assure that themes were appropriately grouped. Additionally, two community forums were conducted to allow for input on the representativeness of the results for Muslim young people. During these forums the broad themes derived were discussed and refined in order to affirm meanings inferred by the researcher. These results did not change the structure of the themes derived, but rather clarified their content. Thus the interpretive analysis was iterative in nature, seeking to understand how the themes represented the lived experiences of Muslim youth in New Zealand.

\section{Results and Discussion}

Three major themes were deduced (see Table 2), (1) resources in acculturation (family, the intercultural environment, and religion), (2) risks in acculturation (cultural differences and discrimination), and (3) outcomes of acculturation (adaptation). These three themes are not mutually exclusive, meaning that some of the issues overlap with one another. Furthermore, it must be noted that many of issues which are mentioned throughout this section are not necessarily unique to Muslim youth.

Table 2. Themes Derived

\begin{tabular}{ll}
\hline Themes & Sub-themes \\
\hline Resources in Acculturation & - Family \\
& - Intercultural Environment \\
& Religion \\
Risks in Acculturation & - Cultural Differences \\
Outcomes of Acculturation & - Adaptation \\
\hline
\end{tabular}

\section{Resources}

The concept of resources refers to factors which are external to the individual that may potentially help youth overcome risk. These resources were available to all of the young people who participated in the study to various degrees, although they were not all utilized in the same way. Therefore, resources can be seen as elements of the environment which have the potential to buffer risks of acculturation. 


\section{The Family}

While it is well-established that families are the most important context where culture is transmitted to young people (Kagitçibasi, 2003), the family can also offer ongoing support and reiteration of cultural values in everyday life. In fact, for the young people in this study, family support was seen as the driving force behind achieving a coherent sense of self (both in terms of ethnicity and religiosity), and in turn, successfully adjusting to New Zealand society. Families were also found to be important in terms of socializing the young person to be open and accepting, and encouraging adaptive coping.

(Family) is important for understanding who you are, your identity. . family support and knowledge are the most important to be a successful Muslim here. Knowledge you can always work on, family support must be there already.

Furthermore, family relationships helped to consolidate connectedness while living in a predominantly individualistic social environment. For individuals who grow up in family-oriented cultures, being interdependent can be an important part of one's self concept, therefore living in a place where relationships were seen as less important than one's individual goals can be challenging (Supple, Ghazarian, Frabutt, Plunkett, \& Sands, 2006). The following quote illustrates how interdependent values can be preserved through family interaction: "Sometimes it feels like I am losing the connected part of me. But I can keep this alive just by being with my family here."

Another important feature of family for Muslim young people were family obligations, or their perceived responsibilities to do well for the sake of the family, to make others proud of their achievements, and to represent themselves well in their new environment (Fuligni, Tseng, \& Lam, 1999). For the participants in this study, obligations to the family encouraged behavior that was in line with cultural and religious expectations. Often youth were faced with the choice of whether to remain faithful and embedded within their religion and culture, or to "let go" and assimilate to ways of behaving in New Zealand society.

I'm the oldest and I have to set an example for my sisters, which I find really hard, extremely hard. Sometimes I just want to let it go, but I'm like nah, you have to do this for your family.

The above quote suggests that even though adaptation to the New Zealand environment is difficult at times, responsibilities to family (rather than to the self) tended to be regarded as of paramount importance. 


\section{The Intercultural Environment}

The second theme of resources in acculturation is the intercultural environment, or the setting in which acculturation takes place. Although the majority of participants believed that New Zealand was a beautiful, peaceful place to live, there were some challenges faced with regards to access to Islamic infrastructure such as mosques, halal ${ }^{2}$ butchers, and Islamic schools. While the establishment of proper infrastructure for an Islamic way of life was an important component of successful adaptation, challenges to practicing their faith were often viewed as opportunities for reinterpretation and confirmation of their beliefs, as is illustrated by the following quote:

I was quite open about it... I knew the flexibility in our religion and stuff like that. I actually put that flexibility into practice when I was here.

Whether or not participants had arrived in New Zealand with the knowledge of a need for flexibility around their religious practice, many indicated that they had made attempts to deal with the lack of facilities, and being able to confidently practice their faith regardless of the barriers was seen as empowering. This is illustrated in the diverse accounts provided about finding creative places to conduct prayer, for example, the changing rooms in a mall and the bathrooms in a sports stadium. As the following quote exemplifies, rising to challenges presented by the New Zealand environment led participants to be much more aware of the importance of their religious practice:

Because when I'm in (my home country), we have everything and sometimes we don't see it, but being here we don't really have it, but we do actually have it. I mean we have to find it if we want to have it. It's like, if you want it you have to go and get it. But in (my home country) everything's there. Here it's your choice whether you grab it or not.

The sentiment of this young woman, "here we don't really have it, but we do actually have it" indicates that all one really needs when facing a lack of infrastructure is the desire to find new ways of doing things in order to overcome whatever constraints there may be outside of oneself.

The concepts of diversity and multiculturalism were an element of the intercultural environment that were seen as encouraging positive adaptation. Specifically, multiculturalism was seen as a social resource which fostered openness and acceptance, and a personal resource, making the participant's experience in New Zealand "more interesting" and allowing people "to be them-

2. Meaning permissible by the Islamic faith 
selves." Such statements indicate that for the young Muslims in this study, multiculturalism has wide ranging effects, not just on the culture at large or their ability to integrate, but on their personal experiences of change and growth.

The importance of multiculturalism was also reflected in the community of Muslims living in New Zealand who are ethnically diverse, and are bound by shared beliefs and values rather than ethnic ancestry. Many of the participants stressed that ethnic diversity within the community was an important factor in defining themselves in the New Zealand context. The following focus group participant describes the experience of actively constructing a "Muslim environment" in the New Zealand setting:

We still have a Muslim environment. Even though we see ourselves as minority here in New Zealand, we are all very close compared to (my home country). Because even though (my home country) is a Muslim country, when we walk on the street ... they don't really smile, they have their own business. But here when we see Muslim people it's, 'assalamu alaikum!' we click with them, talk to them.

In the preceding quote the participant reframed the negative elements of being a visibly different member of a "minority" group by suggesting that it is actually the fact that they are different that enables Muslims to locate each other in their social space and make connections. When the participant was a member of the religious majority in her home country, being Muslim was not a salient social identity. Residing in New Zealand, it becomes much more important to be able to recognize other people's religious identities and to create social situations in which communalities are evident. Thus, meeting a stranger on the street and greeting them with the traditional Islamic "assalamu alaikum"s is a powerful way to assert and mobilize identity. Furthermore, the following quote suggests that for these young people, religion transcends ethnicity when understanding the connections that are being made between people:

We feel we are connected with them because of our religion and ... we all are the same. Even though they have different backgrounds like Indian and Arab, still we're the same. And we kind of feel connected with them because we're a small group so we feel like we have to do that. Actually, it's not that "we have to", we feel like we belong to a group and it's really great to know all of these different people.

The connections exist because community members are all "the same." Overcoming the differences between adherents (specifically with regards to ethnicity) is particularly important for this community, as the participant notes "we're

3. This is an Arabic statement which is often translated as Peace be upon you. 
a small group." As another participant said "our beliefs make our differences smaller," meaning that it is what is shared between Muslims that is important. Being Muslim was felt to be about a shared a set of beliefs, but also about "doing the same thing", or how a Muslim should behave. This connotes that connection between members of the Muslim community actually arises through shared worldviews that influence all aspects of a young person's lived experience.

For the young people in this study, an important element of belonging to an ethnically heterogeneous community is that it taught them to be open to diverse opinions and ways of living, Not only do young people in the Muslim community have the opportunity to learn (and to have others learn from them) about other cultures and ways of life, meeting Muslims from other backgrounds can also educate Muslim youth about diversity in interpretations of Islam itself. Through coming together in order to negotiate differences, the most basic, shared elements of Islamic teaching (removed from their embeddedness in cultural ritual) can be made salient.

\section{Religion}

The third resource Muslim young people could access was their religious beliefs and practices. For the young people who took part in this study, religion affected all areas of their life, meaning that it informed their attitudes and behaviors, as well as influencing the way the young people defined themselves.

I really, truly believe every single thing that is good about me is because I am a Muslim and every single thing that is not so good about me is because of my innate problems as a person, as a human being.

The development of a sense of self worth and character as a Muslim was very much embedded in the ideological teachings of Islam, particularly with regards to the continuation of the spirit in the afterlife.

We are taught that whatever you do, you get back. If you do bad things then you are punished, if you do good then you will be rewarded. Sometimes these rewards and punishments come straight to you, and other times heaven and hell are rewards and punishments, and that is afterlife. Right now this belief reminds me all the time who I need to be.

In this sense, faith is intrinsically motivating and it pushed the youth to constantly strive to be "good" Muslims. However, the shift to New Zealand made it particularly difficult to uphold these values because being a member of a minority group meant they were not afforded a lot of societal support for their 
religious principles. Therefore, the young people in this study indicated that they felt a huge amount of responsibility, and even fear, in maintaining their religious identity and practices.

Now (I have moved to New Zealand) everything depends on me. I hold the control. I think I have the same amount of faith than I did before. But now it is all on me, this is a fear of mine, how do I be a good Muslim?

In some situations, this sense of responsibility also forced young people to learn more about their religion and to better understand what it meant to them to be a Muslim.

Back home being Muslim was not a big issue, so I didn't actually have to know my religion that much. So I took it for granted, but coming to a foreign country I actually had to know more about my religion, I took the initiative to equip myself, so that if people ask me questions I can answer them and be proud of my religion. . . coming to a foreign country actually got me closer to my religion.

For the participants in this study, the protective function of religion was embedded in the process of acculturation. As illustrated in the above quote, the experience of coming to a foreign country inspired them to learn about their religion. The knowledge of being a religious minority and the need to take responsibility for one's own beliefs and values was the catalyst for exploring the function of their religion and beginning to position themselves as learners, teachers, and experts in their belief system. The process of actively and consciously striving to maintain the centrality of religion in their everyday lives was protective, as it enabled connections to be created with forces bigger than themselves and formed a stable base of values and principles to guide attitudes and behavior.

Religiosity was not only important in protecting against the negative elements of acculturation, it also greatly influenced the way the young Muslims in this study approached intercultural or interfaith interactions. According to many of the participants, Islamic teachings proscribe respect for all other faiths, meaning that non-Muslims must be treated with openness and all faiths must be regarded with the utmost significance, as one young man said, "Our religion says that we have to respect every person, even though I am a Muslim and you are not a Muslim I have to respect that."

Furthermore, Islamic teachings state that Muslims should attempt to teach others about their beliefs. Therefore, some of the participants felt as though it was their responsibility to inform, or educate others about Islam. Therefore, the participants in this study were applying their faith in order to cope with the 
lack of knowledge concerning their Islam and subsequently were reframing their minority status to a position of power, developing themselves into educators about their faith.

\section{Risks in Acculturation}

Risks

The concept of risk refers to factors that may potentially create difficulties for youth to be able to adjust successfully in their environment. The risks outlined in this section were experienced by all of the young Muslims who participated in the study to various degrees, although they were not all experienced as highly stressful or harmful. Therefore, the themes presented in this section should be viewed as elements of the acculturation process which have the potential to create stress and lead to negative adjustment for Muslim youth in New Zealand, but do not necessarily do so for a variety of reasons.

\section{Cultural Differences}

Often incongruence between one's heritage culture and the society of settlement is the major cause of stress experienced by immigrants. Cultural distance can exacerbate perceived cultural differences and lead to increased difficulty in the society of settlement (Zlobina, Basabe, Paez, \& Furnham, 2006). The greater the cultural distance, the more cultural learning is required to 'fit in' and thus the more potential stress or risk there is associated with adjusting to the host culture (Ward, 2001; Ward, Bochner, \& Furnham, 2001; Ward \& Kennedy, 1993). This research found that perceived cultural differences do cause stress for Muslim youth, and consequently present risks for successful adaptation. For the participants in this study the place where cultural differences were the most evident was in comparison between their own lifestyles and those of young New Zealanders. This was particularly true with regards to how New Zealanders socialize and what they are perceived to value:

I guess socializing here revolves around drinking, so that was something that is difficult for a Muslim to come here and actually embrace. Because all the events, all the cocktail parties I've been to, all the work nights I've been to, all the award functions revolve around drinking in the end. I mean drinking is seen as the key to socializing in the Kiwi culture. 
Many of the participants felt that it was necessary to offer an explanation for their behavior in an attempt in maintain their beliefs while also participating in social activities that involved others consuming alcohol, or indeed engaging in a variety of other haram $^{4}$ activities. This situation was not ideal, and for a few of the young people caused a great deal of distress. In the following quote, a young woman discusses such a situation in her work place:

Today they were having a sweepstake (at work) . . . and they asked me if I wanted to do it, and I said, "Oh no it's like gambling, I'm not going to go into that." .. Someone came up to me and they nudged me and said, "Oh, it's not part of your religion?" and they were just being funny, and I looked at them real seriously and I was like, "No. and I'm not going to do it either." and then he was like, "Oh, okay." But it was a moment for both of us.

The crux of the problem described by the above quote is the "moments" that this young woman discusses where differences become the central element of interactions. The salience of difference was discussed by the participants with regard to alcohol, gambling, halal food, and especially to female dress style, the wearing of hijab ${ }^{5}$ and body contact between men and women. The following quote exemplifies the frustration and guilt one young woman felt from consistently having to make clear to men who she met that she was unable to shake hands with them:

When I meet boys they try to shake my hand, I feel sorry for them, I don't want to embarrass them but I can't help it. Sometimes I want to have a page and write "I can't." and have this with me always.

Furthermore, issues of cultural difference were made even more complicated by language difficulties that constrained the ability for these young people to convey the intricacy and importance of the things which made them different. As one young woman said, "We can't really simply give them brief explanation because we need to give an in-depth definition for them to get the full concept of Islam." This quote indicates that the issue at hand is not language per se, but rather what another participant deemed as "not enough ways to explain".

For the young Muslims in this study differences between themselves and host nationals were embedded in their worldviews and not in the particular practices that signalled to others they were different. Being able to explain the way they looked and acted was a matter of being able to elucidate their deep

4. An Arabic term meaning forbidden

5. An Arabic term meaning modesty, but also referring to the covering of hair or covering of the body. 
religious beliefs. The following quote illustrates this concept through the discourse of a "culture barrier":

Mainly there's like a culture barrier. You can't communicate well because of our language. It's really hard to communicate to other people. Most of the lifestyle, like how people talk and act and understand each other is completely different.

The cultural barrier that is experienced by Muslim immigrants in New Zealand is a product of two separate, albeit interrelated concepts. The first is the lack of care and attention host nationals put into understanding cultural differences, rather than just tolerating them or even outright judging others because they are different. The second is the feeling and expectation many Muslim youth carry that they are different and therefore, will be treated with less respect than other people. With regards to the first point, there was a consensus among participants that New Zealanders were generally apathetic, but not hostile, toward other people; "I guess it's about the individualistic thing as well; they're more involved about their own stuff." With regards to the second point concerning the expectations participants had about being accepted by the wider society, when the individual had negative expectations this lead to feeling of being lonely and isolated.

And I always feel that I am different. I always feel that I look different, I have an accent. I'm not like everyone else; I don't drink, I don't go clubbing, I don't have a boyfriend - I'm not allowed to.

For this young woman, being seen as different was tantamount to being excluded from the New Zealand society. The elements of difference that are described in the above quote are visible ways in which the participant diverged from host nationals. It seems that she was more concerned about differences that might be noticed, rather than internal differences (e.g., beliefs and values). The quote below also refers to noticeable differences and expectations of being excluded because of these differences:

So I remember I used to go home in front of the mirror and practice talking in a Kiwi accent so that I wouldn't be different ... I remember doing things like this that I wasn't comfortable with just to be integrated.

From the above quote it seems as though some Muslim youth may understand being integrated as 'passing', or not calling attention to the differences between themselves and New Zealanders. In this way one may be more able to feel as if 
they belong and are legitimate members of the New Zealand society. For some of the participants feeling different was experienced as restricting and distressing: "You realize that you're a stranger here, and it's not easy being a stranger. And you feel like the odd one out; you feel very different."

However the young woman went on to say that this feeling passed as soon as she let go of the expectation of not being accepted, and embraced the fact that she was not the same as everyone else:

So you have these people who don't really care if you're different or new or whatever and at the same time I expected them to be interested because I was different, so I had these conflicting two ideas, but eventually I just realized, it's different, there is no right or wrong, it's just different. And this is the way they are and no matter what happens I shouldn't be sad.

\section{Discrimination}

Muslim young people tend to be seen as particularly vulnerable to discrimination as they are recognizably different to both host nationals and other migrant groups. Also, because they belong to a stigmatized group that often features negatively in international media, majority members potentially have preconceived and misinformed notions about this group. Muslim women who wear hijab are particularly visible in Western contexts. In fact it has been suggested that wearing hijab has become a loaded symbol upon which the themes of oppression, docility, and "otherness", are projected (Zine, 2001). Confirming previous research, this study it was found that the female participants perceived they were discriminated against because of their appearance "I do feel like people are afraid to approach me because I wear hijab." Furthermore, the majority of participants were also of the opinion that host nationals were not adequately informed about Islam, and in fact held a variety of misconceptions that were damaging to Muslims.

So they think that women are being forced to wear the scarf and that we have arranged marriages, and that we're living in deserts, and that we know nothing about the world... like NZ is heaven to us, and we're living in deserts and camps and camels and stuff. . . but they wouldn't really tell you what they think because they feel embarrassed to and they don't want you to know that this is what they think.

As this participant indicates, misunderstandings of Islam were perceived to be wide-spread, although these this did not necessarily translate into overt 
instances of discrimination. The young woman states that New Zealanders "wouldn't really tell you" what they think of Muslims, rather their attitudes can be deduced based on the ways they treated these young people and the types of questions that they ask. The perception Muslim youth have of these questions is that they are tinged with implicit judgement about the legitimacy of their beliefs and practices. The young people in this study had very few first-hand experiences of explicit prejudice in the New Zealand environment. When they did have these experiences, rather than overt discrimination, the encounters reflected the ignorance of difference in general.

So I was talking to people and suddenly this lady walks up to me and says, "Oh your English is really good, eh." And I was like, how can you make a comment like that? I've actually just won a prize (for top in my course), of course I can speak some English! So you know comments like that can actually hurt you at times.

In many ways implicit types of discrimination are as damaging, or even more so, than explicit forms of prejudice. This is because they undermine values and identities but are very difficult to directly confront as they can easily be denied. In actuality, it is not only subtle prejudice that undermines beliefs, the general lack of understanding by New Zealanders of Islam can act to devalue Muslim youth's sense of self, even when the other person may have good intentions or make attempts to be inclusive.

I pray 5 times a day and it's like someone saying, "Let's go have coffee, it's just one time." This is not right, not only for religion but I would like people in general to be sensitive to other people's values.

For some of the participants, the misconceptions held by the majority of host nationals were an inevitable part of life that exists due to the apathy inherent in New Zealand culture. However for others, being misunderstood could become an opportunity to reframe their own experiences. In the following quote, a female participant recounts a distressing intercultural exchange she had with a male New Zealander:

People are always like, "Oh, why do Muslims ..." and sometimes they say it with sarcasm, someone even said to me "Oh please. I don't understand why you wouldn't shake hands. My hand is not made out of pork." And all of these comments. And I would get really affected.

This young woman was confronted with an individual who had some knowledge of Islamic culture, in that he understood Muslims do not consume pork. 
However, he uses this information to be condescending about the nature of restrictions on gendered interactions. In many ways, this individual's prejudice against Islam is apparent in his "question" about her religious practices. The young women went on to discuss the ways she coped with such experiences:

I felt it was my duty to answer their questions. I couldn't just tell them, "I don't feel comfortable doing that," because I felt this was an opportunity, maybe God was going to ask me, "Why didn't you answer them? This was your opportunity to make them know." So sometimes it got really tough and I felt very bad about myself and my self esteem was really bad, but then I got over it. And the same guy who was telling me, "My hand is not made of pork," he came to a talk that they gave about Islam, so I felt that eventually things were changing and it really depends on the way you look at it.

Even if Muslim youth were able to somehow frame their experiences of discrimination in a way which enabled them to better cope with their circumstances, every single participant mentioned that they were concerned with the way that Islam was portrayed, not just in New Zealand, but on an international scale. The most distressing, and most common, misunderstanding held by non-Muslims was that Islam condones and supports terrorism. While the participants indicated that some adherents were indeed involved in terrorist activities, all agreed that these individuals did not understand the true concept of Islam and were misguided in their beliefs concerning the use of violence; "It's true, some of them (Muslims) are. They've been misguided. They misunderstand the Quran.” Rather than place blame on New Zealanders for having stereotypical notions of Muslims, it was generally the case that the young people in this study accepted that negative portrayals of Islam were inevitable given the current socio-political milieu.

But I can't do much about it. It's not like I can go to newspaper and tell them to stop doing that. That's why I think if you want to correct that I should lead by example. If the media says that Islam is violent then I should not be violent. I think that if we are misunderstood, then we correct them, that is all.

This meant letting go of anger towards others for what they do wrong and taking responsibility to teach people about themselves as well as maintaining confidence and adherence to their beliefs.

At this stage you do find people who just make fun of you and you have to learn how to respond to them in a cool way without getting angry. Teach them, no, that's not how it is. 
While at the same time, staying true to themselves:

Well, I don't think I should hate them because it's what they are thinking. I cannot control them. But it's kind of sad, if people do not see you the way you want them to see you. But I won't actually show them what they want to see, I will show them who I actually am.

In order to achieve this, the participants felt that they had to take the lead in breaking down misconceptions, and to try to positively reframe their situation.

I remember all of the times that I was offended. All of the times that people said rude comments about Islam and Muslims, and then I would feel upset. But after that, what? If I satisfy the feeling that people are racist and they hate Muslims, and then what? It just would make me upset and that's it. And at the same time if I want to think about how many times people said very nice things about Islam and Muslims, I could do that too. So I think it really depends on how you take it.

Or look to their faith for guidance:

And the last sermon, [Prophet Muhammad] was talking about a whole bunch of things and one of the things he said was, "Just remember that an Arab is not any better than a non-Arab, a black is not better than a white." And I thought, 1400 years ago, and he was reminding us in the last sermon not to let race get into the way, genders aren't supposed to come in the way. . . No matter what the media says, I know that I'm equal with respect to my being to someone else.

While these young people did feel a lot of responsibility for changing the mindset of those who held prejudicial and misinformed attitudes about Islam, there was a strong sense that in order to effectively reduce discrimination there must be mutual respect and understanding. In fact, New Zealanders were not expected to know all about Islam, but they were expected to be open and accepting of difference. The following quote summarizes the feelings of the participants towards fair and equitable treatment in the New Zealand environment:

I guess it would just be a more understanding among different races, different cultures, and stuff like that ... If people actually just opened up their mouth and start talking, everything would be fine. Cause once people they start to learn and they start to realize that people aren't bad, and you know we're not 
as different, people are generally the same. We can connect with one another, even though we come from different races and different countries and different parts of the world, we still have the same values and enjoy the same things in life, so you know. I guess it's just communication with people is key to solving all the issues.

As this young man suggests, opening up a dialogue between people from diverse backgrounds can effectively minimize differences and promote effective intercultural interactions. Most importantly, the concept of communication as a way of combating discrimination captures the need for a shared solution between Muslims and the wider society.

\section{Outcomes of Acculturation}

The third theme, outcomes of acculturation, broadly refers to whether or not individuals are able to successfully negotiate the experience of cultural transition. Outcomes of acculturation were not mentioned as frequently as the elements of the other two themes, mainly due to the fact that there was a focus on the process, rather than the actual state of settling into a new cultural environment. Also, for the young people in this study, the social and psychological outcomes of acculturation were deeply embedded in their everyday lived experiences. In this study, outcomes are defined as accounts of what changed for the participants as a result of moving the New Zealand and whether they feel happy, comfortable and functional in this environment.

For all individuals undergoing acculturation, cultural, psychological and behavioral changes are inevitable (Berry, 2005). These changes, or adaptations, are primarily driven by the need to function effectively in a culturally complex environment. In the acculturation literature, it is widely found that strategies of integration, or adapting elements of one's ethnic culture at the same time as adopting elements of the national culture, leads to the best outcomes for immigrant youth. Integration is generally thought to be preferred option for immigrant youth (particularly in societies with multicultural ideologies) because this strategy enables the individual to negotiate their distinct social worlds more successfully (Phinney \& Devich-Navarro, 1997). Effectively, when a young person is competent in their heritage culture and the culture of the wider society they are able to better manage the potentially incongruent demands places upon them by these distinct orientations (Sam \& Oppedal, 2002; Stuart \& Ward, 2011). In this study it was found that being able to integrate multiple identities was an effective way to deal with the process of acculturation. As the following quote suggests, even though cultural transition may be difficult in the beginning, integrating the distinct elements of the self enabled this young woman to deal with the difficulties of acculturation: 
Yeah. Maybe I had a bit of trouble when I was younger, when I first came. Because it was kind of hard to adapt to their culture and to what they do. But then you sort of adapt and you can embrace all of them. This made it so much easier.

It is not just the outcome of being integrated, it was also the process of becoming integrated, that helped these young people adjust more successfully. As one young man said "We tried to pick and choose from both cultures... you have an advantage of choosing the best qualities of the two cultures.

Because of the unique nature of social identities for Muslim youth, integration conceptually becomes more complex as it involves the relationship between one's ethnic, religious, and host national identities. However, the results indicate that participants did not necessarily perceive religion as an identity which is integrated with one's cultural identity. Rather, it was constructed as an overarching set of principles and behaviors that other identities (and the product of integrating of these identities) reside under.

Yeah, I guess. You have two cultural sides, a Western and an Eastern influence. I don't particularly stick to one side. I sort of embrace both. And then there's the spiritual identity. And that's Islam. It's not just a religion, but it's a way of living and a way of life. How you go about doing things and stuff.

All participants indicated that it was a very difficult to adapt to their new cultural environment and that "embracing" one's different cultural orientations did assist them in their acculturation. However, it was also mentioned that not all young Muslims were able to get to a place where they could become integrated because they were not open to change. Many of the participants indicated that they believed being closed off to the experience of living in a new culture was the major reason why other Muslims may not do well in New Zealand.

People who didn't actually get the chance ... they didn't actually give themselves a chance to experience the whole new environment they were in, they were so busy just being worried about how they're going to take care of themselves in the way they were brought up to be and just stick to their roots and their culture and stuff. So they didn't actually enjoy the experience that I get to enjoy.

Participants suggested that being aware of their expectations about how they would be perceived by New Zealanders, and attempting to find new ways of understanding themselves was the key to successful adaptation. Effectively, self awareness enabled these young people to be able to reframe their negative experience and empowered them to make changes in their lives. 
If you want to believe that people are racist around you, you would find something that would satisfy this thing. And if you put into your mind that people are friendly, you would also find something to satisfy that. So it's whatever you put in your mind when dealing with people, "Ah, see? They hate Muslims." So I really think it is about how you view things and how you put things into your mind, and it's all because of the fear. But I think you can overcome the fear by interacting with people.

While the experience of adjustment was difficult, the majority of participants felt that it led to positive change in their lives. For the following young woman this meant being able to develop and achieve her goals:

It is better for us I think because we are away from our country, a Muslim country. Here we're adapting, we now have our aspirations and we have a place to make that happen.

And for this young woman it meant living up to her potential, specifically discovering her "powers" to be successful and independent. In the end, participants suggested that maintaining one's beliefs, being open to change while remaining a strong person with principles was seen as "the only way" to successfully adjust to the New Zealand environment.

\section{Conclusion}

The findings of this study offer insights into the lived experiences of Muslim immigrant youth in New Zealand, particularly concerning how they define themselves and their successful adaptation. The overall conceptual framework developed from the qualitative information in this study indicates that being embedded in the process of acculturation is a defining factor in how these young people understand themselves and their social worlds. Specifically, the results capture three distinct facets of the acculturation process that emerged as important for these Muslim youth: resources, risks, and outcomes.

Muslim youth face a variety of risks that predominantly arise from exposure to discrimination and engagement in the process of cultural transition. According to developmental theories, this experience of stress is not unique to minorities, all youth encounter stressful events that can pose a threat to the development of competent behavioral and psychological outcomes (Arrington \& Wilson, 2000; Harvey \& Delfabbro, 2004). The context for youth adaptation can be conceptualized along a continuum, with one end representing the precursors to stable, adaptive functioning and the other end representing the factors that contribute to maladaptation (Arrington \& Wilson, 2000). It has 
been found that young people who are exposed to negative circumstances, particularly those who are minorities, consequently face stressors above and beyond those normatively occurring in the developmental period (Arrington \& Wilson, 2000; Spencer \& Dupree, 1996). Despite serious threats to development, some of these youth continue to exhibit competency in their everyday lives, a phenomenon that has been labelled resilience (Arrington \& Wilson, 2000; Fergus \& Zimmerman, 2005; Masten, 2001).

The results of this study indicate that resources are important for how young Muslims understand their experiences of adaptation, both in the way they perceive stressors as well as how they achieve positive outcomes. While Muslim youth in New Zealand may be at risk of negative adaptation outcomes, because of their exposure to the stress of dealing with cultural differences and discrimination, resources may counteract the effect of these stressors serving a protective role, and they may also play a promotive role by having a direct positive effect on adaptation. In fact, for the participants in this study, successful adaptation was achieved by offsetting the degree of risk or stress that was experienced with the potential resources at their disposal. Therefore, while it was the case that the stressors produced by discrimination and cultural difference were challenging, residing in a culturally plural context, having supportive family networks as well as maintaining religious beliefs and practices helped these young people become resilient.

It is suggested that at the intersection of acculturation and normative development, there is an emergent pathway of resilience by which Muslim youth arrive at positive outcomes. This pathway is embedded within a context of stress (discrimination and cultural transition) and is mitigated by potential resources in the young person's environment (intercultural, family, and religious factors). Because resources are important for how young Muslims understand their experiences of adaptation, practitioners working with this group of young people could benefit from taking a strengths-based approach rather than a deficit or risk-based approach. As such, it is suggested that applications of these findings take a positive youth development approach in order to enable young people underdoing cultural transition to reframe acculturative stressors as normal parts of building resilience.

This research took an in-depth, exploratory approach in order to elucidate the most important factors involved in cultural transition for Muslim youth in New Zealand. This research was limited by the size of the sample and the broad nature of the themes, meaning that generalizable conclusions about what predicts successful adjustment for this group cannot be drawn. However, the information drawn from this in-depth study on adaptation of Muslim youth in New Zealand can help us to better understand the experiences of immigrant youth in Western contexts. Specifically, the results illustrate that regardless of experiences of risk, Muslim youth are adapting well in New Zealand. As such, 
the lessons learned by this group of young people, and coping mechanisms that they demonstrate may be utilized by other ethnic minority and immigrant youth in order to develop resilience.

\section{References}

Anwar, M. (1998). Between cultures: Young Muslims in Britain: Attitudes, educational needs and policy implementation. Leicester, UK: The Islamic Foundation.

Archer, L. (2001). 'Muslim brothers, black lads, traditional Asians': British Muslim young men's constructions of race, religion and masculinity. Feminism and Psychology, 11(1), 79-105. http://dx.doi.org/10.1177/0959353501011001005

Arrington, E. G., \& Wilson, M. N. (2000). A re-examination of risk and resilience during adolescence: Incorporating culture and diversity. Journal of Child and Family Studies, 9(2), 221-230. http://dx.doi.org/10.1023/A:1009423106045

Balsano, A. B., \& Sirin, S. R. (2007). Commentary on the special issue of ADS Muslim youth in the West: "Collateral damage" we cannot afford to disregard. Applied Developmental Science, 11(3), 178-183. http://dx.doi.org/10.1080/10888690701454690

Beckford, J. A., Glae, R., Owen, D., Peach, C., \& Weller, P. (2006). Review of the evidence base on faith communities. London, UK: Office of the Deputy Prime Minister.

Berry, J. W. (1997). Immigration, acculturation, and adaptation. Applied psychology: An international review, 46(1), 5-98.

Berry, J. W. (2005). Acculturation: Living successfully in two cultures. International Journal of Intercultural Relations, 29, 697-712. http://dx.doi.org/10.1016/j.ijintrel.2005.07.013

Boyatzis, R. (1998). Transforming qualitative information: Thematic analysis and code development. Thousand Oaks, CA: Sage.

Braun, V., \& Clarke, V. (2006). Using thematic analysis in psychology. Qualitative Research in Psychology, 3(2), 77-101. http://dx.doi.org/10.1191/1478088706qp063oa

Fergus, S., \& Zimmerman, M. A. (2005). Adolescent resilience: A framework for understanding healthy development in the face of risk. Annual Review of Public Health, 26, 399-419. http://dx.doi.org/10.1146/annurev.publhealth.26.021304.144357

Floersch, J., Longhofer, J. L., Kranke, D., \& Townsend, L. (2010). Integrating thematic, grounded theory and narrative analysis: A case study of adolescent psychotropic treatment. Qualitative Social Work, 9(3), 1-19. http://dx.doi. org/10.1177/1473325010362330

Franz, B. (2007). Europe's Muslim youth: An inquiry into the politics of discrimination, relative deprivation, and identity formation. Mediterranean Quarterly, 18(1), 89-112. http://dx.doi.org/10.1215/10474552-2006-036

Fuligni, A. J., Tseng, V., \& Lam, M. (1999). Attitudes toward family obligations among American adolescents with Asian, Latin American, and European backgrounds. Child Development, 70(4), 1030-1044. http://dx.doi.org/10.1111/1467-8624.00075

Harvey, J., \& Delfabbro, P. H. (2004). Psychological resilience in disadvantaged youth: A critical overview. Australian Psychologist, 39(1), 3-13. http://dx.doi.org/10.1080 /00050060410001660281

HRC. (2010). Freedom of religion and belief. Wellington, New Zealand: Human Rights Commission.

Inglehart, R., \& Norris, P. (2009). Muslim integration into Western cultures: Between 
origins and destinations: HKS Working Paper Series: RWP-007. Harvard Kennedy School of Government.

Kagitçibasi, Ç. (2003). Autonomy, embeddedness and adaptability in immigration contexts. Human Development, 46(2-3), 145-150. http://dx.doi. org/10.1159/000068584

Kolig, E., \& Kabir, N. (2008). Not friend, not foe: The rocky road of enfranchisement of Muslims into multicultural nationhood in Australia and New Zealand. Immigrants \& Minorities, 26, 266-300. http://dx.doi.org/10.1080/02619280802528502

Kong,L.(2010).Globalshifts, theoreticalshifts:Changinggeographiesofreligion.Progress in Human Geography, 34, 755-776. http://dx.doi.org/10.1177/0309132510362602

Masten, A. (2001). Ordinary magic: Resilience processes in development. American Psychologist, 56(3), 227-238. http://dx.doi.org/10.1037/0003-066X.56.3.227

Ministry of Social Development. (2008). Diverse communities: Exploring the migrant and refugee experience in New Zealand. Wellington, NZ: Ministry of Social Development.

Oppedal, B., \& Røysamb, E. (2007). Young Muslim immigrants in Norway: An epidemiological study of their psychosocial adaptation and internalizing problems. Applied Development Science, 11(3), 112-125. http://dx.doi. org $/ 10.1080 / 10888690701454583$

Phinney, J. S., \& Devich-Navarro, M. (1997). Variations in bicultural identification among African American and Mexican American adolescents. Journal of Research on Adolescence, 7(1), 3-32. http://dx.doi.org/10.1207/s15327795jra0701_2

Patton, M. Q. (2002). Qualitative research and evaluation methods (3rd ed.). Newbury Park, CA: Sage.

Pew Research Center. (2009). Mapping the global Muslim population: A report on the size and distribution of the world's Muslim population. Washington, DC: The Pew Global Attitude Project.

Robinson, L. (2009). Cultural identity and acculturation preferences among South Asian adolescents in Britain: An exploratory study. Children and Society, 23, 442454. http://dx.doi.org/10.1111/j.1099-0860.2008.00179.x

Sam, D. L. (2006). Acculturation: Conceptual background and core components. In D. L. Sam \& J. W. Berry (Eds.), The Cambridge handbook of acculturation psychology (pp. 11-26). Cambridge: Cambridge University Press. http://dx.doi.org/10.1017/ CBO9780511489891.005

Sam, D. L., \& Oppedal, B. (2002). Acculturation as a developmental pathway. In W. J. Lonner, D. L. Dinnel, S. A. Hayes \& D. N. Sattler (Eds.), Online Readings in Psychology and Culture. ,WA: Western Washington University, Center for CrossCultural Research.

Sam, D. L., Vedder, P., Ward, C., \& Horenczyk, G. (2006). Psychological and sociocultural adaptation of immigrant youth. In J. W. Berry, J. S. Phinney, D. L. Sam \& P. Vedder (Eds.), Immigrant youth in cultural transition: Acculturation, identity, and adaptation across national contexts (pp. 117-142). Mahwah, NJ: Lawrence Erlbaum.

Sirin, S. R., \& Fine, M. (2007). Hyphenated selves : Muslim American youth negotiating identities on the fault lines of global conflict. Applied Development Science, 11, 151-163. http://dx.doi.org/10.1080/10888690701454658

Sirin, S. R., \& Fine, M. (2008). Muslim American youth: Understanding hyphenated identities through multiple methods. New York: New York University Press.

Smith, J. I. (2002). Introduction. In Muslims in the West (pp. 3-16). Oxford, U.K.: Oxford University Press. http://dx.doi.org/10.1093/acprof:oso/9780195148053.003.0001 
Spencer, M. B., \& Dupree, D. (1996). African-American youths' ecocultural challenges and psychosocial opportunities: An alternative analysis of problem behavior outcomes. In D. Cicchetti \& S. L. Toth (Eds.), Adolescence: Opportunities and challenges (pp. 259-282). Rochester, NY: University of Rochester Press.

Statistics New Zealand. (2011). Requested statistics, derived from NZStat. Retrieved from http://www.stats.govt.nz/tools_and_services/nzdotstat.aspx.

Stuart, J., \& Ward, C. (2011). A question of balance: Exploring the acculturation, integration and adaption of Muslim immigrant youth Psychosocial Intervention, 20, 255-267.

Stuart, J., Ward, C., \& Adam, Z. (2010). Current issues in the development and acculturation of Muslim youth in New Zealand. International Society for the Study of Behavioral Development Bulletin, 2(58), 9-13.

Supple, A. J., Ghazarian, S. R., Frabutt, J. M., Plunkett, S. W., \& Sands, T. (2006). Contextual influences on Latino adolescent ethnic identity and academic outcomes. Child Development, 77, 1427-1433. http://dx.doi.org/10.1111/j.1467-8624.2006.00945.x

Ward, C. (2001). The A, B, Cs of Acculturation. In D. Matsumoto (Ed.), The Handbook of Culture and Psychology (pp. 411-445). Oxford, UK. : Oxford University Press.

Ward, C., Bochner, S., \& Furnham, A. (2001). The psychology of culture shock (2nd ed.). East Sussex, UK: Routledge.

Ward, C., \& Kennedy, A. (1993). Psychological and sociocultural adjustment during cross-cultural transitions: A comparison of secondary students overseas and at home. International Journal of Psychology, 28, 129-147. http://dx.doi. org/10.1080/00207599308247181

Ward, C., Liu, J., Fairairn-Dunlop, T. P., \& Henderson, A. K. (2010). Youth voices youth choices: Identity, integration and social cohesion in culturally diverse Aotearoa/ New Zealand, Science And Technology. Wellington, New Zealand.

Zine, J. (2001). Muslim youth in Canadian schools: Education and the politics of religious identity. Anthropology and Education Quarterly, 32, 399-423. http://dx.doi. org/10.1525/aeq.2001.32.4.399

Zlobina, A., Basabe, N., Paez, D., \& Furnham, A. (2006). Sociocultural adjustment of immigrants: Universal and group-specific predictors. International Journal of Intercultural Relations, 30(2), 195-211. http://dx.doi.org/10.1016/j.ijintrel.2005.07.005 